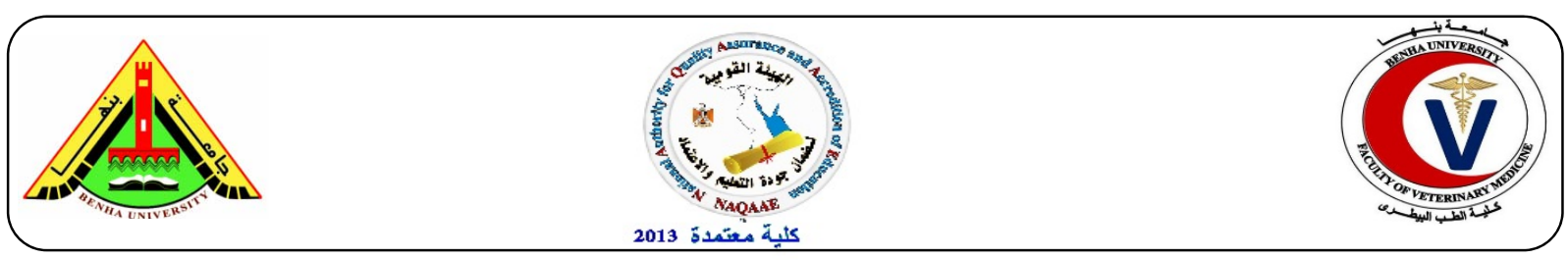

\title{
Incidence and antibiogram of Clostridium perfringens isolated from herbs and spices widely distributed in the Egyptian market.
}

\author{
Ashraf Abd El-Tawab ${ }^{1}$, Mohamed Abdallah ${ }^{2}$, Hend Yusuf ${ }^{2 *}$ \\ ${ }^{1}$ Department of Microbiology, Faculty of Veterinary Medicine, Benha University, 13736 Moshtohor, EGYPT; \\ ${ }^{2}$ Department of Microbiology, Central Lab of Residue Analysis of Pesticides \& Heavy Metals in Food, Agricultural \\ Research Center, Ministry of Agriculture, 12311 Giza, Egypt. Corresponding author: dr.hendyusuf@gmail.com. +202 \\ 37611355
}

\section{A B S T R A C T}

\begin{abstract}
The present study was designed for isolation and identification of Clostridium perfringens (C. perfringens) from herbs and spices that are widely distributed in the Egyptian markets; and determination of the drug of choice for its control based on the Antimicrobial Susceptibility Test (AST). A total of 392 samples of herbs and spices were randomly and anonymously selected from the enormous number of samples obtained from the Egyptian markets. An overall occurrence of C. perfringens was $8.42 \%$ (33 out of 392). Separately, occurrence was higher in herbs than spices being 10.5 and $6.25 \%$, respectively. C. perfringens isolates were identified and confirmed with macroscopical, microscopical and biochemical analysis. AST results revealed that isolates of $C$. perfringens from the tested herbs and spices samples were found most susceptible to ampicillin-sulbactam and Penicillin-G with inhibition zones of $19.4 \pm 0.98$ and $16.6 \pm 1.16$ mm, respectively. On the other hand, the isolates were found nearly resistant to clindamycin and vancomycin with inhibition zones of 6.28 \pm 0.63 and $8.78 \pm 0.41 \mathrm{~mm}$, respectively. Meanwhile, the isolates were intermediary susceptible to trimethoprimsulphamethoxazole combination and chloramphenicol. Data of the present study indicate occurrence of $C$. perfringens in herbs and spices with a considerable rate and the antimicrobials of choice for its control are penicillins and ceftazidime. higher sanitation procedures in herbs and spices industry before its distribution to the Egyptian markets have been recommended.
\end{abstract}

Keywords: C. perfringens, Incidence, Prevalence, Herbs, Spices, AST.

(http://www.bvmj.bu.edu.eg) $\quad$ (BVMJ-32(1): 198-206, 2017)

\section{INTRODUCTION}

Clostridium perfringens (C. perfringens; formerly known as Clostridium welchii, or Bacillus welchii) is a Gram-positive, rod-shaped, anaerobic, spore-forming pathogenic bacterium of the genus Clostridium (Ryan and Ray, 2004). It is ever present in nature and can be found as a normal component of decaying vegetation, marine sediment, the intestinal tract of humans and other vertebrates, insects, and soil. It has the shortest reported generation time of any organism at 6.3 minutes in thioglycollate medium (Bionumbers, 2016). C. perfringens is a major cause of human and veterinary enteric disease largely because this bacterium can produce several toxins when present inside the gastrointestinal tract (Smedley Iii et al., 2004). The bacterium causes human gas gangrene and food poisoning as well as several enterotoxemic diseases of animals (Rood, 1998). Spices often act as important vectors for various microorganisms, especially spore formers implicating possible health problems for consumers; among these microorganisms is $C$. perfringens and its enterotoxin (Banerjee and Sarkar, 2004); (Aguilera et al., 2005). Contaminated spices have been reported to cause foodborne illness and spoilage. Fewer microorganisms are present in spices with higher antimicrobial activity such as sage, cloves, and oregano. Therefore, all spices and herbs should be cleaned and decontaminated with ethylene oxide, irradiation, or other acceptable methods (Giese, 1994). Spices and herbs are considered as a potential source of infection with $C$. perfringens where they may be contaminated because of conditions in which they were grown and harvested. The spores of $C$. perfringens were proved to be present in spices and herbs by (Kneifel and Berger, 1994) and (Pafumi, 1986). A few studies have been tried to assess the incidence of $C$. perfringens in herbs and spices eilsewhere worldwide, including South Africa (Baxter and Holzapfel (1982), Austria 
(Kneifel and Berger (1994), Mexico (RodríguezRomo et al. (1998), India (Banerjee and Sarkar (2003), Turkey (Hampikyan et al. (2009), United Kingdom (Sagoo et al. (2009), Italy (Vitullo et al. (2011), Lebanon (Debs-Louka et al. (2013), Saudi Arabia (Hassan and Altalhi (2013), However, to our information, no parallel study has been performed in Egypt.

Therefore, the aim of the present study was to investigate the incidence (prevalence) of $C$. perfringens in herbs and spices delivered to and distributed all over the Egyptian markets and to determine the antimicrobial of choice for its control. To fulfil this aim, the following objectives have been investigated: i) isolation of $C$. perfringens from the randomly selected samples; ii) identification of $C$. perfringens in isolates macroscopically, microscopically and biochemically; and iii) antibiotic sensitivity testing of C. perfringens in identified isolates.

\section{MATERIALS AND METHODS}

\subsection{Samples}

Three hundred and ninety-two samples obtained from the Egyptian markets have been tested for incidence of $C$. perfringens in the present study. Table (1) shows the detailed descriptions of samples used.

\subsection{Isolation of $C$. perfringens \\ 2.3. Preparation of test sample:}

The samples were prepared in accordance with ISO $6887-2$, ISO 6887-3, ISO 6887-4 or ISO 8261.

\subsubsection{Test portion, initial suspension and dilutions:}

This was done according to ISO 6887 or ISO 8261. Ten $\mathrm{g}$ of each sample was taken and diluted with 90 $\mathrm{ml}$ maximal recovery diluent (MRD) then mixed well in stomacher and $1 \mathrm{ml}$ was then inoculated into a sterile test tube containing $9.0 \mathrm{ml}$ of MRD. This inoculated suspension was then serially diluted into further tubes containing $9.0 \mathrm{ml}$ MRD.

\subsubsection{Inoculation and incubation (Poured-plate technique):}

By means of a sterile pipette, $1 \mathrm{ml}$ of the initial prepared suspension (or of the test sample if the initial product is liquid) was transferred, in duplicate, to the centers of sterile petri dishes. Then, 10 to $15 \mathrm{ml}$ of the perfringens agar base with its supplements maintained at $44^{\circ} \mathrm{C}$ to $47^{\circ} \mathrm{C}$ in the water bath, were poured into the dish and mixed well with the inoculum by gentle rotation. When the medium solidified, an over-layer of $10 \mathrm{ml}$ of the same perfringens agar base agar was added. The plates were incubated under anaerobic conditions at $37^{\circ} \mathrm{C}$ for $20 \pm 2 \mathrm{hrs}$.

\subsection{Identification of $C$. perfringens}

Identification of $C$. perfringens was accomplished by classical microbiological techniques including, macroscopical appearance and culture characters of grown colonies according to hemolysis (Brett, 1994); microscopical appearance after Gram staining (Oxoid, Code: R40080) of a film prepared from a pure culture according to Beveridge (2001) and by biochemical tests according to schemes of Koneman et al. (1992) using the following tests: Catalase, gelatin hydrolysis, sugar fermentation, indole test, nitrate reduction, urease and lecithinase activity.

\subsection{Antimicrobial Susceptibility Test (AST)}

Antimicrobial Susceptibility Testing was performed using the Kirby-Bauer Disc Diffusion method (Biemer, 1973). The following discs have been used: Ampicillin $10 \mu \mathrm{g}+$ sulbactam $10 \mu \mathrm{g}$ (SAM 20), Chloramphenicol $30 \mu \mathrm{g}$ (C 30), Ciftazidium + Clavulanic acid (CAL 40), Clindamycin $2 \mu \mathrm{g}$ (CD 2), Erythromycin $15 \mu \mathrm{g}$ (E 15), Norfloxacin $10 \mu \mathrm{g}$ (NOR 10), Penicillin G 10 units (PG 10), Tetracycline $30 \mu \mathrm{g}$ (T30), Trimethoprim $1.25 \mu \mathrm{g}+$ Sulphamethoxazole 23.75 $\mu \mathrm{g}$ (TS 25) and Vancomycin $5 \mu \mathrm{g}$ (VA 5).

\subsection{Data management and Statistical analysis}

The obtained results were statistically analyzed using EXCEL ${ }^{\circledR}$ software version 2013. The number of positive samples against the total number of examined samples was calculated as \%. AST was done in triplicates; and inhibition zones were calculated as Mean \pm SEM of three observations.

\section{RESULTS}

\subsection{Incidence of $C$. perfringens in the tested herbs and spices}

As shown in Table (2), out of 392 herbs and spices samples obtained from Egyptian markets, totally, 33 isolates were detected with an incidence of $8.42 \%$. The incidence of $C$. perfringens in herbs was $10.5 \%$ (21 out of 200 Samples) and in spices was $6.25 \%$ (12 out of 192). Table (3) shows the incidence of C. perfringens in herb samples while table (4) shows its incidence in spice samples.

\subsection{Identification of $C$. perfringens isolates}

\subsubsection{Culture characters}

on blood base agar with $7 \%$ sterile blood, $C$. perfringens colonies were $2-3 \mathrm{~mm}$ in diameter, rounded, raised, glistening and showed double 
zone of haemolysis. On TSC agar, C. perfringens colonies were black in colour.

\subsubsection{Microscopical examination}

Smears were done from characteristic colonial appearance, stained with Gram's stain and examined under oil immersion lens. C. perfringens isolates appeared to be Gram positive short plumb bacilli rarely having central oval non-bulging endospores.

\subsubsection{Nagler's test}

On egg yolk agar medium, the effect of alpha toxin on lecithin gave opalescence on the half of the plate without antitoxin while this was inhibited on the second half with antitoxin. Also all isolates demonstrated positive results in lecithinase activity on TSC agar containing egg-yolk emulsion.

\subsubsection{DNAse test}

DNAse test was done for all C. perfringens isolates and nearly $69.7 \%$ (23 out of 33 ) gave positive result indicated by pink halo around the streaks.

\subsubsection{Biochemical identification}

Results of biochemical tests were confirmative to C. perfringens; where results of sugar fermentation test revealed that the isolates were positive for glucose, lactose and sucrose sugars while mannitol fermentation was negative. The isolates liquefied gelatin while catalase and indole were negative.

\subsubsection{Antimicrobial Susceptibility Testing results}

Results of AST are shown in Table (5) with inhibition zones $(\mathrm{mm})$ produced by 10 antibacterials against $C$. perfringens isolates from herbs and spices. C. perfringens were highly sensitive to ampicillin + salbactam and Penicillin$\mathrm{G}$ with inhibition zones of $19.4 \pm 0.98$ and $16.6 \pm$ $1.16 \mathrm{~mm}$, respectively. Meanwhile, the isolates were resistant to clindamycin and vancomycin with inhibition zones of $6.28 \pm 0.63$ and $8.78 \pm 0.41 \mathrm{~mm}$, respectively. Sulphamethoxazol-trimethoprim combination and chloramphenicol gave intermediate efficacy with inhibition zones of 14.6 \pm 0.84 and $13.8 \pm 0.51$, respectively.

Table (1): List of herbs and spices tested for incidence of C. Perfringens

\begin{tabular}{lccccc}
\hline Item name & Item description & Number of samples & Item name & Item description & $\begin{array}{c}\text { Number of } \\
\text { samples }\end{array}$ \\
\hline Anise & Herb & 5 & Black pepper & Spice & 7 \\
Basil & Herb & 45 & Capsicum & Spice & 6 \\
Caraway & Herb & 5 & Cheese & Spice & 18 \\
Chamomile & Herb & 5 & Cheese + Onion & Spice & 18 \\
Calendula & Herb & 5 & Cilantro & Spice & 10 \\
Dill & Herb & 10 & Coriander & Spice & 15 \\
Fennel & Herb & 20 & Cumin & Spice & 6 \\
Henna & Herb & 5 & Hot chilli & Spice & 30 \\
Majoram & Herb & 50 & Onion & Spice & 50 \\
Mint (Dry) & Herb & 20 & Olive & Spice & 15 \\
Parsley & Herb & 20 & Thyme & Spice & 12 \\
Rose Mary & Herb & 5 & Verbascum & Spice & 5 \\
Sage & Herb & 5 & & & 192 \\
Number of Herbs & & 200 & & Number of spices & \\
Total number of samples & & & 392 & \\
\hline
\end{tabular}


Table (2): Incidence of C. perfringens in examined herbs and spices samples

\begin{tabular}{llll}
\hline Type Of Samples & $\begin{array}{l}\text { Number of } \\
\text { Tested samples }\end{array}$ & $\begin{array}{l}\text { Number of +ve } \\
\text { Samples }\end{array}$ & Incidence \% \\
\hline Herbs & 200 & 21 & 10.5 \\
Spices & 192 & 12 & 6.25 \\
Overall & 392 & 33 & 8.42 \\
\hline
\end{tabular}

Table (3): Incidence of C. perfringens in examined herb samples

\begin{tabular}{llll}
\hline Item Name & No. of Samples & Positive Samples & Incidence \% \\
\hline Anise & 5 & 1 & 20 \\
Basil & 45 & 4 & 8.9 \\
Caraway & 5 & 0 & 0 \\
Chamomile & 5 & 2 & 40 \\
Calendula & 5 & 1 & 20 \\
Dill & 10 & 1 & 10 \\
Fennel & 20 & 1 & 5 \\
Henna & 5 & 1 & 20 \\
Majoram & 50 & 6 & 12 \\
Mint (Dry) & 20 & 1 & 5 \\
Parsley & 20 & 1 & 5 \\
Rose Mary & 5 & 0 & 0 \\
Sage & 5 & 2 & 40 \\
\hline
\end{tabular}

Table (4): Incidence of C. perfringens in examined spice samples

\begin{tabular}{lccc}
\hline Item Name & No. of Samples & Positive Samples & Incidence \% \\
\hline Black pepper & 7 & 0 & 0 \\
Capsicum & 6 & 0 & 0 \\
Cheese & 18 & 0 & 0 \\
Cheese + Onion & 18 & 1 & 5.6 \\
Cilantro & 10 & 2 & 20 \\
Coriander & 15 & 0 & 0 \\
Cumin & 6 & 1 & 16.7 \\
Hot chilli & 30 & 1 & 3.3 \\
Onion & 50 & 5 & 10 \\
Olive & 15 & 0 & 0 \\
Thyme & 12 & 1 & 8.3 \\
Verbascum & 5 & 1 & 20 \\
\hline
\end{tabular}


Table (5): Inhibition zones (mm) produced by 10 antibacterials against $C$. perfringens isolates from herbs and spices.

\begin{tabular}{|c|c|c|c|c|c|c|c|c|c|c|}
\hline Sample & SAM20 & PG10 & CAL40 & E15 & CD2 & TS25 & T30 & NOR10 & VA5 & C30 \\
\hline \multirow{3}{*}{1} & 13.33 & 5.17 & 4.23 & 8 & 5 & 9 & 8 & 10.67 & 8 & 11 \\
\hline & \pm & \pm & \pm & \pm & \pm & \pm & \pm & \pm & \pm & \pm \\
\hline & 0.88 & 0.44 & 0.39 & 0.58 & 0.58 & 0.58 & 0.58 & 0.67 & 0.58 & 0.58 \\
\hline \multirow{3}{*}{2} & 11.17 & 16.27 & 4.93 & 10.03 & 5.23 & 20.03 & 7.2 & 10.1 & 5.03 & 20.03 \\
\hline & \pm & \pm & \pm & \pm & \pm & \pm & \pm & \pm & \pm & \pm \\
\hline & 0.60 & 0.64 & 0.35 & 0.32 & 0.28 & 0.32 & 0.42 & 0.55 & 0.20 & 0.26 \\
\hline \multirow{3}{*}{3} & 25 & 25.2 & 20.17 & 10.07 & 7.33 & 5.2 & 10.1 & 5.23 & 10.97 & 10.07 \\
\hline & \pm & \pm & \pm & \pm & \pm & \pm & \pm & \pm & \pm & \pm \\
\hline & 1.15 & 0.81 & 0.38 & 0.23 & 0.38 & 0.47 & 0.21 & 0.39 & 0.32 & 0.41 \\
\hline \multirow{3}{*}{4} & 25.03 & 25.1 & 17.5 & 5.07 & 5.1 & 15.07 & 6.07 & 9.17 & 12.1 & 12.97 \\
\hline & \pm & \pm & \pm & \pm & \pm & \pm & \pm & \pm & \pm & \pm \\
\hline & 0.260 & 0.15 & 0.29 & 0.12 & 0.21 & 0.35 & 0.23 & 0.38 & 0.21 & 0.26 \\
\hline \multirow{3}{*}{5} & 27 & 20.03 & 19.87 & 10.07 & 15 & 15.1 & 8.07 & 14.9 & 12.03 & 15.17 \\
\hline & \pm & \pm & \pm & \pm & \pm & \pm & \pm & \pm & \pm & \pm \\
\hline & 0.29 & 0.20 & 0.24 & 0.23 & 0.58 & 0.38 & 0.35 & 0.32 & 0.26 & 0.38 \\
\hline \multirow{3}{*}{6} & 17.03 & 20.3 & 10.27 & 7.93 & 5.03 & 14.93 & 8.1 & 10.83 & 7.07 & 15.97 \\
\hline & \pm & \pm & \pm & \pm & \pm & \pm & \pm & \pm & \pm & \pm \\
\hline & 0.43 & 0.35 & 0.37 & 0.23 & 0.55 & 0.41 & 0.49 & 0.38 & 0.52 & 0.32 \\
\hline \multirow{3}{*}{7} & 20.07 & 18.2 & 14.3 & 10.03 & 5.07 & 15.17 & 9.93 & 8.13 & 7.23 & 14.03 \\
\hline & \pm & \pm & \pm & \pm & \pm & \pm & \pm & \pm & \pm & \pm \\
\hline & 0.23 & 0.25 & 0.35 & 0.32 & 0.23 & 0.27 & 0.23 & 0.47 & 0.34 & 0.09 \\
\hline \multirow[t]{2}{*}{8} & NA & NA & NA & NA & NA & NA & NA & NA & NA & NA \\
\hline & 20.07 & 5.13 & 15.1 & 5.07 & 4.03 & 15 & 9.03 & 8.1 & 5.07 & 15 \\
\hline \multirow[t]{2}{*}{9} & \pm & \pm & \pm & \pm & \pm & \pm & \pm & \pm & \pm & \pm \\
\hline & 0.35 & 0.24 & 0.26 & 0.52 & 0.15 & 0.58 & 0.55 & 0.49 & 0.35 & 0.58 \\
\hline \multirow{3}{*}{10} & 15.17 & 10 & 18.03 & 5 & 5.17 & 15 & 9 & 9.13 & 6.07 & 12.07 \\
\hline & \pm & \pm & \pm & \pm & \pm & \pm & \pm & \pm & \pm & \pm \\
\hline & 0.44 & 0.58 & 0.32 & 0.58 & 0.44 & 0.58 & 0.58 & 0.41 & 0.52 & 0.23 \\
\hline \multirow{3}{*}{11} & 20 & 18.1 & 15 & 10.23 & 5 & 10 & 4.88 & 5.2 & 10 & 14.97 \\
\hline & \pm & \pm & \pm & \pm & \pm & \pm & \pm & \pm & \pm & \pm \\
\hline & 0.58 & 0.21 & 0.58 & 0.28 & 0.58 & 0.58 & 0.30 & 0.36 & 0.58 & 0.20 \\
\hline \multirow{3}{*}{12} & 15 & 10 & 5 & 6.23 & 5 & 10.17 & 6 & 8.1 & 5.3 & 14.93 \\
\hline & \pm & \pm & \pm & \pm & \pm & \pm & \pm & \pm & \pm & \pm \\
\hline & 0.29 & 0.58 & 0.58 & 0.34 & 0.29 & 0.27 & 0.58 & 0.15 & 0.57 & 0.29 \\
\hline \multirow{3}{*}{13} & 15 & 18 & 5 & 11 & 5 & 15 & 13.03 & 10.03 & 6.16 & 13.03 \\
\hline & \pm & \pm & \pm & \pm & \pm & \pm & \pm & \pm & \pm & \pm \\
\hline & 0.29 & 0.58 & 0.58 & 0.12 & 0.29 & 0.58 & 0.26 & 0.55 & 0.55 & 0.55 \\
\hline \multirow{3}{*}{14} & 30.03 & 23 & 20.03 & 13 & 17.97 & 8.1 & 10 & 15 & 10.1 & 16 \\
\hline & \pm & \pm & \pm & \pm & \pm & \pm & \pm & \pm & \pm & \pm \\
\hline & 0.55 & 0.58 & 0.26 & 0.58 & 0.26 & 0.55 & 0.58 & 0.17 & 0.26 & 0.58 \\
\hline \multirow{3}{*}{15} & 23 & 17.03 & 8.03 & 3 & 3 & 15 & 8 & 10.23 & 8 & 11 \\
\hline & \pm & \pm & \pm & \pm & \pm & \pm & \pm & \pm & \pm & \pm \\
\hline & 0.58 & 0.26 & 0.32 & 0.58 & 0.29 & 0.58 & 0.58 & 0.34 & 0.58 & 0.58 \\
\hline & 20 & 20.1 & 16.97 & 11.97 & 10 & 16.97 & 16.03 & 15.07 & 13 & 15.03 \\
\hline 16 & \pm & \pm & \pm & \pm & \pm & \pm & \pm & \pm & \pm & \pm \\
\hline & 0.58 & 0.55 & 0.32 & 0.26 & 0.58 & 0.15 & 0.49 & 0.35 & 0.58 & 0.26 \\
\hline & 25.03 & 27.13 & 22.4 & 15.03 & 10.07 & 5 & 8.1 & 8.03 & 10.1 & 5 \\
\hline 17 & \pm & \pm & \pm & \pm & \pm & \pm & \pm & \pm & \pm & \pm \\
\hline & 0.38 & 0.52 & 0.31 & 0.15 & 0.52 & 0.58 & 0.49 & 0.26 & 0.55 & 0.58 \\
\hline & 12 & 7.03 & 6.03 & 10 & 5.03 & 3 & 3.03 & 3.03 & 10.03 & 5.97 \\
\hline 18 & \pm & \pm & \pm & \pm & \pm & \pm & \pm & \pm & \pm & \pm \\
\hline & 0.58 & 0.43 & 0.55 & 0.58 & 0.26 & 0.58 & 0.26 & 0.55 & 0.61 & 0.26 \\
\hline & 22.03 & 21.03 & 16.03 & 5 & 5.03 & 18 & 8.06 & 11.1 & 10.07 & 15.1 \\
\hline 19 & \pm & \pm & \pm & \pm & \pm & \pm & \pm & \pm & \pm & \pm \\
\hline & 0.26 & 0.15 & 0.55 & 0.58 & 0.43 & 0.40 & 0.52 & 0.55 & 0.52 & 0.55 \\
\hline & 17.1 & 7 & 20.03 & 5.1 & 5 & 15 & 4.97 & 15.03 & 4.97 & 15 \\
\hline 20 & \pm & \pm & \pm & \pm & \pm & \pm & \pm & \pm & \pm & \pm \\
\hline
\end{tabular}




\begin{tabular}{|c|c|c|c|c|c|c|c|c|c|c|}
\hline & 0.26 & 0.58 & 0.09 & 0.26 & 0.06 & 0.58 & 0.09 & 0.49 & 0.26 & 0.58 \\
\hline & 6 & 4.97 & 6.03 & 2.9 & 3.07 & 14.97 & 7 & 8.03 & 7.07 & 12.03 \\
\hline \multirow[t]{3}{*}{21} & \pm & \pm & \pm & \pm & \pm & \pm & \pm & \pm & \pm & \pm \\
\hline & 0.58 & 0.20 & 0.61 & 0.21 & 0.23 & 0.55 & 0.58 & 0.55 & 0.64 & 0.55 \\
\hline & 30.07 & 25.03 & 9 & 15.07 & 7 & 16.03 & 11.07 & 6.03 & 12 & 15.07 \\
\hline \multirow[t]{3}{*}{22} & \pm & \pm & \pm & \pm & \pm & \pm & \pm & \pm & \pm & \pm \\
\hline & 0.29 & 0.55 & 0.58 & 0.35 & 0.58 & 0.26 & 0.52 & 0.26 & 0.52 & 0.41 \\
\hline & 20.07 & 20.03 & 16.1 & 10.1 & 5 & 22.07 & 10.1 & 12.1 & 7 & 18.03 \\
\hline \multirow[t]{3}{*}{23} & \pm & \pm & \pm & \pm & \pm & \pm & \pm & \pm & \pm & \pm \\
\hline & 1.10 & 0.96 & 0.49 & 0.496 & 0.58 & 0.23 & 0.55 & 0.44 & 0.58 & 0.32 \\
\hline & 20.03 & 22.07 & 5.07 & 12.03 & 5.03 & 17.13 & 11.17 & 13.17 & 8.17 & 15.13 \\
\hline \multirow[t]{3}{*}{24} & \pm & \pm & \pm & \pm & \pm & \pm & \pm & \pm & \pm & \pm \\
\hline & 0.49 & 0.52 & 0.52 & 0.09 & 0.32 & 0.47 & 0.44 & 0.44 & 0.44 & 0.41 \\
\hline & 18.17 & 16 & 10.1 & 12.07 & 3 & 15.27 & 6.97 & 10.1 & 8.17 & 15.43 \\
\hline \multirow[t]{3}{*}{25} & \pm & \pm & \pm & \pm & \pm & \pm & \pm & \pm & \pm & \pm \\
\hline & 0.27 & 0.58 & 0.38 & 0.29 & 0.58 & 0.32 & 0.26 & 0.49 & 0.44 & 0.34 \\
\hline & 14.97 & 15.1 & 5 & 13 & 4 & 20.13 & 10.03 & 9.17 & 10.07 & 15.07 \\
\hline \multirow[t]{3}{*}{26} & \pm & \pm & \pm & \pm & \pm & \pm & \pm & \pm & \pm & \pm \\
\hline & 0.55 & 0.26 & 0.58 & 0.58 & 0.58 & 0.52 & 0.55 & 0.44 & 0.92 & 0.52 \\
\hline & 15 & 12 & 6.07 & 7 & 4 & 18.17 & 15.03 & 8 & 12.1 & 11.13 \\
\hline \multirow[t]{3}{*}{27} & \pm & \pm & \pm & \pm & \pm & \pm & \pm & \pm & \pm & \pm \\
\hline & 0.58 & 0.58 & 0.35 & 0.58 & 0.58 & 0.22 & 0.09 & 0.58 & 0.38 & 0.47 \\
\hline & 15.23 & 16.33 & 5.03 & 14.2 & 4.97 & 17.17 & 9 & 8.1 & 7.17 & 14.43 \\
\hline \multirow[t]{3}{*}{28} & \pm & \pm & \pm & \pm & \pm & \pm & \pm & \pm & \pm & \pm \\
\hline & 0.45 & 0.60 & 0.20 & 0.36 & 0.09 & 0.73 & 0.58 & 0.49 & 0.44 & 0.54 \\
\hline & 27.5 & 25.47 & 15 & 7 & 5 & 25.5 & 8.17 & 4.97 & 10.07 & 13.33 \\
\hline \multirow[t]{3}{*}{29} & \pm & \pm & \pm & \pm & \pm & \pm & \pm & \pm & \pm & \pm \\
\hline & 0.76 & 0.52 & 0.58 & 0.58 & 0.29 & 0.66 & 0.44 & 0.15 & 0.52 & 0.60 \\
\hline & 15.57 & 12 & 2.87 & 10.17 & 2.9 & 15.43 & 15.4 & 7.17 & 9.3 & 14 \\
\hline \multirow[t]{3}{*}{30} & \pm & \pm & \pm & \pm & \pm & \pm & \pm & \pm & \pm & \pm \\
\hline & 0.72 & 0.58 & 0.19 & 0.44 & 0.21 & 0.54 & 0.67 & 0.44 & 0.35 & 0.58 \\
\hline & 15.63 & 12 & 5 & 14.6 & 5.033 & 18.23 & 10.47 & 10.17 & 10.27 & 15.33 \\
\hline \multirow[t]{3}{*}{31} & \pm & \pm & \pm & \pm & \pm & \pm & \pm & \pm & \pm & \pm \\
\hline & 0.68 & 0.58 & 0.58 & 0.86 & 0.15 & 0.39 & 0.52 & 0.44 & 0.43 & 0.55 \\
\hline & 20.3 & 25.43 & 16.03 & 12.3 & 10.1 & 16 & 10.1 & 8.07 & 11.07 & 15.1 \\
\hline \multirow[t]{3}{*}{32} & \pm & \pm & \pm & \pm & \pm & \pm & \pm & \pm & \pm & \pm \\
\hline & 0.91 & 0.70 & 0.55 & 0.46 & 0.49 & 0.58 & 0.55 & 0.23 & 0.52 & 0.61 \\
\hline & 26.5 & 10 & 10.1 & 15.2 & 15 & 14.07 & 20.6 & 5 & 10 & 15.07 \\
\hline \multirow[t]{3}{*}{33} & \pm & \pm & \pm & \pm & \pm & \pm & \pm & \pm & \pm & \pm \\
\hline & 0.76 & 0.58 & 0.21 & 0.47 & 0.58 & 0.52 & 0.70 & 0.17 & 0.58 & 0.23 \\
\hline & 17.43 & 17.13 & 6 & 17.1 & 5.033 & 10.03 & 15.1 & 9.07 & 6 & 13.03 \\
\hline \multirow[t]{2}{*}{34} & \pm & \pm & \pm & \pm & \pm & \pm & \pm & \pm & \pm & \pm \\
\hline & 0.81 & 0.70 & 0.58 & 0.38 & 0.55 & 0.61 & 0.38 & 0.52 & 0.58 & 0.38 \\
\hline Overall & 19.37 & 16.59 & 11.40 & 9.84 & 6.28 & 14.57 & 9.63 & 9.28 & 8.78 & 13.77 \\
\hline Mean & \pm 0.98 & \pm 1.16 & 1.06 & \pm 0.66 & \pm 0.63 & \pm 0.84 & \pm 0.63 & \pm 0.53 & \pm 0.41 & \pm 0.51 \\
\hline
\end{tabular}

\section{DISCUSSION}

Microbiological evaluation studies to determine the prevalence or extent of occurrence of microbes and their strain identification are principal prerequisites to control or reduce safety hazards in food or feed or their additives. The International Standardization Organization (ISO) has regulated requirements for food safety hazards, including microbiology end point with final goal of human and animal safety and welfare (Seagrave, 2007).
Among microbes carrying the risk of foodborne illness is C. perfringens on which the present study was focused. C. perfringens, formerly welchii, has been known as a cause of the serious wound infection, gas gangrene

In the present study, it has been found that occurrence of $C$. perfringens in the tested herbs and spices samples was $8.42 \%$ ( 33 out of 392 samples). This finding may be parallel to Fujisawa et al. (2001) who found occurrence of C. perfringens in 7 samples from total of $60(12 \%)$ commercially available curry roux samples in Japan. The present 
finding may also comparable to Aguilera et al. (2005) who detected presence of C. perfringens in 14 out of 115 spices samples $(12.17 \%)$ in Argentina. However, the result of the present study may be higher than that reported by Kneifel and Berger (1994) who detected C. perfringens only in one caraway sample out of 160 samples of 55 different spices and herbs originating from six different suppliers and retailed at outlets in Vienna; in the same manner Warmińska-Radyko et al. (2007) detected that none of the examined vegetable salads available at retail stores, supplied by various producers in Poland, contained $C$. Perfringens; and also by Sagoo et al. (2009) who reported incidence value of $0.4 \%$ of $C$. perfringens in dried spices and herbs from production and retail premises in the United Kingdom. On the other hand, the result in the current study was much lower than that found by Powers et al. (1975) who detected an incidence of $15 \%$ of C. perfringens in the spices procured by the Army, Navy, Marines and Air Force is USA especially in oregano samples (53\%); and by De Boer and Boot (1983) who found different incidence rates for $C$. perfringens according to the used media being out of 147 samples, $42 \%$ were positive when RPM was used, $23 \%$ with PEM, $19 \%$ with TSC surface plate and $26 \%$ with TSC pour plates. Moreover, the data are also lower than incidence rate value of $59 \%$ in herbs and spices in India (Banerjee and Sarkar, 2003).

The discrepancy in incidence results may be attributed to various factors including sample sources, sanitation procedures adopted by suppliers, different locations, different materials and methodologies as well as different research environments.

Application of the identification techniques in the present study revealed that on blood base agar with $7 \%$ sterile blood, C. perfringens colonies were 2-3 $\mathrm{mm}$ in diameter, rounded, raised, glistening and showed double zone of haemolysis. While on TSC agar, C. perfringens colonies were black in colour. These findings are in agreement with Brett (1994); Cowan et al. (2004) and Abd Al-Tawab et al. (2015) who isolated C. perfringens from different sources and purified colonies with the same morphological characters. Reference characters of $C$. perfringens colonies were stated by Markey et al. (2013) as grey, flat and often with irregular edge, $2.0-3.0 \mathrm{~mm}$, with double zone of haemolysis.

Once a pure culture is obtained, the results from a few comparatively simple conventional tests can often identify the bacterium to a generic level, including: a Gram-stained smear from the culture will establish the Gram reaction (Gram-positive or
Gram-negative); and the bacterial cell morphology whether cocci or rods ... etc (Markey et al., 2013). Microscopical examination of Gram stained smears form isolates obtained from herbs and spices in the present study revealed that $C$. perfringens isolates appeared to be Gram positive short plumb bacilli rarely having central oval nonbulging endospores. These findings are in agreement with the reference microscopical characters of $C$. perfringens that were stated by Adams and Moss (2005) as a Gram-positive, rodshaped anaerobe which forms oval subterminal spores. It differs from most other Clostridia in that the relatively large rods $\left(\begin{array}{llll}1 & \mathrm{x} & 3-9 & \mathrm{pm})\end{array}\right)$ are encapsulated and nonmotile. The findings are also consistent with those reported by previous researchers as Cato et al. (1986); Rood and Cole (1991); Heredia and Labbé (2001); McClane (2003); and Labbe and Juneja (2006).

Also, all isolates obtained in the present study demonstrated positive results in lecithinase activity on TSC agar containing egg-yolk emulsion. However, the effect of alpha toxin produced from tested isolates on lecithin gave opalescence only on the half of the plate without C. perfringens antitoxin while this was inhibited on the second half with antitoxin. DNAse test revealed that nearly $69.69 \%$ of the isolates were positive. Further biochemical tests were confirmative to $C$. perfringens; where isolates were positive for glucose, lactose and sucrose sugar fermentation; liquefied gelatin while they were negative for catalase and indole tests. The findings may be consistent with parallel studies carried out by Cowan et al. (2004); ISO (2004); Abd Al-Tawab et al. (2015).

To complete such microbiological study circle, it is not enough to just identify the isolated microorganism. It is also needed to elect what antimicrobial agents the microorganism is most susceptible to (Karlowsky and Richter, 2015). Among the several methods used for AST, the Kirby-Bauer method is best incorporating many of the features recommended by the World Health Organization. It is relatively simple from a technological standpoint and accurate and reproducible; Thus it has been applied in the present study. Isolates of $C$. perfringens from the tested herbs and spices samples were found most susceptible ( $>15 \mathrm{~mm}$ inhibition zone) to ampicillin $10 \mu \mathrm{g}$-sulbactam $10 \mu \mathrm{g}$ (SAM 20) and penicillin G 10 units (PG 10). On the other hand, the isolates were found nearly resistant to clindamycin $2 \mu \mathrm{g}$ (CD 2) and vancomycin. The isolates were intermediary susceptible to trimethoprim $1.25 \mu \mathrm{g}+$ sulphamethoxazole $23.75 \mu \mathrm{g}$ (TS 25) and chloramphenicol. Findings of this study section 
may be in partial agreement with Sapico et al. (1972) who found that $C$. perfringens strains were susceptible to penicillin and with poor susceptibility to erythromycin. However, the present findings are not parallel with their results where they found that the strains were susceptible to clindamycin. The AST data is also in agreement with Dutta and Devriese (1980) regarding resistance of $C$. perfringens strains to erythromycin and lincomycin and susceptibility to penicillin. The present data may be in partial parallelism with Marchand-Austin et al. (2014) who found that $C$. perfringens isolates were universally susceptible to penicillin, however, about $14 \%$ of isolates were resistant.

\section{CONCLUSION}

Data of the present study may indicate occurrence of Clostridium perfringens in herbs and spices with a rate of about $8 \%$ and thus these food additives may act as a source of foodborne disease indicated by conventional microbiological techniques. In addition, the Clostridium perfringens isolates were highly susceptible to ampicillin-Salbactam, penicillin and ciftazidium-clavulanic acid, indicated by Antibiotic Susceptibility Test (AST). Accordingly and depending on the data of the present study that may carry biological hazard to both man and animal beings, the authors recommend avoiding of irrational use of herbs and spices as food/feed additives without veterinary supervision; applying the standards of ISO-22000 concerning food safety regulated and labelled by The Egyptian Organization for Standardization and Quality Control (EOS) and International Organization for Standardization (ISO); and developing simple and economic screening field tests to identify different pathogenic bacteria, including $C$. perfringens in food/feed and their additives, including herbs and spices.

\section{REFERENCES}

Abd Al-Tawab, A.A., El-Hofy, F.I., Khater, D.F., Kotb, M.A., 2015. Typing of Clostridium perfringens isolated from some meat products by using PCR. Benha Veterinary Medical Journal 29, 118-123.

Adams, M., Moss, M., 2005. Bacterial agents of foodborne illness - Clostridium perfringens. In, Food Microbiology. The Royal Society of Chemistry 2000, Cambridge, UK, pp. 212-217.

Aguilera, M.O., Stagnitta, P.V., Micalizzi, B., de Guzmán, A.M.S., 2005. Prevalence and characterization of Clostridium perfringens from spices in Argentina. Anaerobe 11, 327334.

Banerjee, M., Sarkar, P.K., 2003. Microbiological quality of some retail spices in India. Food Research International 36, 469-474.

Banerjee, M., Sarkar, P.K., 2004. Growth and enterotoxin production by sporeforming bacterial pathogens from spices. Food Control 15, 491-496.

Baxter, R., Holzapfel, W., 1982. A microbial investigation of selected spices, herbs, and additives in South Africa. Journal of Food Science 47, 570-574.

Beveridge, T.J., 2001. Use of the Gram stain in microbiology. Biotechnic \& Histochemistry 76, 111-118.

Biemer, J.J., 1973. Antimicrobial susceptibility testing by the Kirby-Bauer disc diffusion method. Annals of Clinical \& Laboratory Science 3, 135-140.

Bionumbers, 2016. ID 105474. Available at http://bionumbers.hms.harvard.edu/bionum ber.aspx?id=105474. In, City.

Brett, M., 1994. Outbreaks of food-poisoning associated with lecithinase-negative Clostridium perfringens. Journal of medical microbiology 41, 405-407.

Cato, E., George, W.L., Finegold, S., 1986. Genus clostridium. Bergey's manual of systematic bacteriology 2, 1141-1200.

Cowan, S.T., Barrow, G., Steel, K.J., Feltham, R., 2004. Cowan and Steel's manual for the identification of medical bacteria. Cambridge university press.

De Boer, E., Boot, E., 1983. Comparison of methods for isolation and confirmation of Clostridium perfringens from spices and herbs. Journal of Food Protection $\AA$ 46, 533 536.

Debs-Louka, E., El Zouki, J., Dabboussi, F., 2013. Assessment of the Microbiological Quality and Safety of Common Spices and Herbs Sold in Lebanon. J Food Nutr Disor 2 4, 2.

Dutta, G., Devriese, L., 1980. Susceptibility of Clostridium perfringens of animal origin to fifteen antimicrobial agents. Journal of Veterinary Pharmacology and Therapeutics 3, 227-236.

Fujisawa, T., Aikawa, K., Takahashi, T., Yamai, S., Ueda, S., 2001. Occurrence of clostridia in commercially available curry roux. Food Hygiene and Safety Science 42, 394-397.

Giese, J., 1994. Spices and seasoning blends: A taste for all seasons. Food technology.(USA). 
Hampikyan, H., Bingol, E.B., Colak, H., Aydin, A., 2009. The evaluation of microbiological profile of some spices used in Turkish meat industry. Journal of Food, Agriculture \& Environment 7, 111-115.

Hassan, S., Altalhi, A., 2013. Safety Assessment of Spices and Herbs Consumed In Saudi Arabia: Microbiological Quality and Toxin Production. Life Sci. J 10, 2819-2827.

Heredia, N.L., Labbé, R.G., 2001. Clostridium perfringens. Guide to foodborne pathogens, 133-142.

ISO, E., 2004. 7937: Microbiology of food and animal feeding stuffs-Horizontal method for the enumeration of Clostridium perfringens. Colony-count technique. European Standard, 3rd ed., BSI, London, UK.

Karlowsky, J.A., Richter, S.S., 2015. Antimicrobial Susceptibility Testing Systems. In, Manual of Clinical Microbiology, Eleventh Edition. American Society of Microbiology, pp. 1274-1285.

Kneifel, W., Berger, E., 1994. Microbiological criteria of random samples of spices and herbs retailed on the Austrian market. Journal of Food Protection $\AA$ 57, 893-901.

Koneman, E.W., Allen, S.D., Janda, W., Schreckenberger, P., Winn, W., 1992. Diagnostic microbiology. Koneman EW, Allen SD. Mycobacteria. Philadelphia: JB Lippincott Company, 703-755.

Labbe, R.G., Juneja, V., 2006. Clostridium perfringens gastroenteritis. Foodborne infections and intoxications 3, 137-184.

Marchand-Austin, A., Rawte, P., Toye, B., Jamieson, F.B., Farrell, D.J., Patel, S.N., 2014. Antimicrobial susceptibility of clinical isolates of anaerobic bacteria in Ontario, 2010-2011. Anaerobe 28, 120-125.

Markey, B., Leonard, F., Archambault, M., Cullinane, A., Maguire, D., 2013. Clinical veterinary microbiology. Elsevier Health Sciences.

McClane, B.A., 2003. Clostridium perfringens. Food Science and Technology-New YorkMarcel Dekker, 91-104.

Pafumi, J., 1986. Assessment of the microbiological quality of spices and herbs. Journal of Food Protection $\AA$ 49, 958-963.

Powers, E.M., Lawyer, R., Masuoka, Y., 1975. Microbiology of processed spices. Journal of
Milk and Food Technology (JMFT) 38, 683687.

Rodríguez-Romo, L.A., Heredia, N.L., Labbé, R.G., García-Alvarado, J.S., 1998. Detection of enterotoxigenic Clostridium perfringens in spices used in Mexico by dot blotting using a DNA probe. Journal of Food Protection ${ }^{\circledR}$ 61, 201-204.

Rood, J.I., 1998. Virulence genes of Clostridium perfringens. Annual Reviews in Microbiology 52, 333-360.

Rood, J.I., Cole, S.T., 1991. Molecular genetics and pathogenesis of Clostridium perfringens. Microbiological Reviews 55, 621-648.

Ryan, K., Ray, C., 2004. Sherris medical microbiology: an introduction to infectious diseases. 4th. In. McGraw Hall USA, City.

Sagoo, S., Little, C., Greenwood, M., Mithani, V., Grant, K., McLauchlin, J., De Pinna, E., Threlfall, E., 2009. Assessment of the microbiological safety of dried spices and herbs from production and retail premises in the United Kingdom. Food microbiology 26, 39-43.

Sapico, F.L., Kwok, Y.-Y., Sutter, V.L., Finegold, S.M., 1972. Standardized antimicrobial disc susceptibility testing of anaerobic bacteria: in vitro susceptibility of Clostridium perfringens to nine antibiotics. Antimicrobial agents and chemotherapy 2, 320-325.

Seagrave, P., 2007. ISO 22000: food safety management systems and their related requirements. In: Sixth world congress on seafood safety, quality and trade, pp. 153157.

Smedley Iii, J., Fisher, D., Sayeed, S., Chakrabarti, G., McClane, B., 2004. The enteric toxins of Clostridium perfringens. In, Reviews of physiology, biochemistry and pharmacology. Springer, pp. 183-204.

Vitullo, M., Ripabelli, G., Fanelli, I., Tamburro, M., Delfine, S., Sammarco, M., 2011. Microbiological and toxicological quality of dried herbs. Letters in applied microbiology 52, 573-580.

Warmińska-Radyko, I., Łaniewska-Trokenheim, Ł., Mikš, M., 2007. Microbiological contamination of vegetable salads. PUBLISHER UWM, 733. 